\title{
CAN THE TRANSFORMATION OF INSTRUCTION PROCESS INTO A VIRTUAL PLACE INDUCE A SHIFT IN BEHAVIORAL PATTERNS OF TEACHERS AND STUDENTS?
}

\author{
Eugen Ljajko $^{1 *}$, Vladica Stojanović ${ }^{1}$, Dragana Valjarević ${ }^{1}$, Tanja Jovanović ${ }^{1}$
}

${ }^{1}$ Faculty of Sciences and Mathematcs, University of Priština, Kosovska Mitrovica, Serbia.

ABSTRACT
The goal of this study is to reveal possible
influence that the participants age and
Information and Communications Technologies
(ICT) usage in the instruction process can have on
behavior that defines whether students and
teachers belong to one of the Digital
Native/Immigrant or Visitor/Resident groups. We
collected data through two surveys that covered a
total of 1273 students and 382 teachers from
southern regions of Serbia. The surveys consisted
of questions about availability of computers and
internet, ICT use in the instruction process, and
communication habits in the ICT-empowered
instruction process. The first survey covered both,
students and teachers that were involved in the

instruction process mostly deprived of the ICT usage. The second survey covered participants of an instruction process that was successfully improved by an ICT usage. Data analysis shows a shift in communication patterns of teachers and a sharp improvement in computer use for educational purposes for both groups included in the surveys. The change is induced by a proper ICT usage in the instruction process. Conclusions that followed the data analysis lead us to better approaches in organizing ICT usage in the instruction process that enable participants fully employ their resources in order to improve teaching techniques and learning.

Key words: Digital natives/immigrants, Visitors/residents, Behavioral patterns, ICT-enriched instruction, Virtual places.

\section{INTRODUCTION}

With Information and Communications Technologies (ICT) introduced in the instruction process, inquiries of new relations between teachers and students, as well as ways participants of the instruction process relate to the technologies and use them, come to the focus. Though the differences in the ways the generations of teachers and students understood and experienced concepts and procedures were observable earlier, it was not clear were they sharper or alleviated after ICT introduction. The differences mostly refer to the way an individual approaches acquisition, understanding and application of the knowledge and skills in the new environment. Therefore, generations of students born after substantial ICT introduction in the instruction process are considered to be different than those born before it.

The mission of equipping Serbian schools with ICT has been carried out partly through the "Digital school" (Digitalna škola) programme of Serbian Ministry of Telecommunications. The program was very successful, and around $95 \%$ (2808) of participating schools were supplied with at least one computer classroom, (Strategija, 2013). Other sources ((Ibro, 2011), (Herceg, 2007)) portray a similar image of ICT availability in Serbian schools.

There are more opinions among the authors concerning the connection between the knowledge, skills and habits to use ICT in instruction process and the group (mostly defined by age) the person belongs to. The opinions could roughly be divided into two streams. Some of them ((Prensky, 2001 a), (Zur, \& Zur, 2011), (Tapscott 2009), (Jukes, Mccain, \& Crockett 2010), (Cunningham 2007)) attribute higher skills to younger participants, while others ((Bullen ET al., 2011), (White \& Le Cornu, 2011), (Bennett \& Maton, 2010), (Oblinger, \& Oblinger, 2005)) hold that the level of skills and habits depends on context instead. Therefore, questions arise:

Do the students and teachers of our schools actually belong to different groups concerning the ICT usage, and, if yes, what are the criteria that define a person's belonging to a group or another? 
Answers to these questions are needed to define better ways to organize an ICT-enriched instruction that would be more effective in terms of knowledge transmission/acquisition and quality of knowledge obtained by students.

Digital natives/digital immigrants dichotomy

(Prensky, 2001a) proposed a sharp social division concerning a person's relation to the ICT usage. According to him, there are two groups diametrically opposed concerning their relation to the ICT usage: Digital Immigrants and Digital Natives. The division is mostly based on habits different generations have in interactions with ICT in different aspects of their lives, which unsurprisingly leads to a conclusion that most, if not all of todays' students, are Digital Natives and, similarly, majority of todays' teachers are Digital Immigrants. This, further, reflects on their interrelations within schools. Discussions by other researchers diverged in different directions.

Some of them discuss stratification within each of these two groups. The groups, according to them, are not as homogenous as Prensky tried to present them. (Zur \& Zur, 2011) offer a stratification within each of them in terms of a person's attitudes and capacities in regard to digital technologies.

Regardless on the way the division is described, there is still a generational clash between groups of teachers (parents, employers, etc.) on one side, and students (children, employees, etc.) on the other side at school, home or work (Zur \& Zur 2011). In regard with relations between the generations, the stratification proposed by Zur \& Zur does not offer a different point of view than the Prensky's one.

The Digital Natives/Digital Immigrants dichotomy and its variations imply differences between the groups concerning ways they think or build knowledge ((Prensky 2001 b), (Tapscott, 2009), (Kelly et al., 2009), (Cunningham 2007)). As a result of Digital Natives' way of thinking and knowledge building, many authors and researchers ((Prensky, 2001 b), (Tapscott 2009), (Kelly et al., 2009), (McNierney, 2004), Howell, 2012)) propose a new way of teaching Digital Natives. According to them, it should be implemented mostly through Digital Immigrants adaptation to youngsters' behavior built by Digital Natives' life-long "immersion into ICT world". However, concerns arise whether parts of knowledge built by Digital Immigrants without ICT will be lost in such a process?
Some researchers consider similar stratifications regardless on a person's age - and therefore not complying with Digital Native/Digital Immigrant dichotomy. (Toledo, 2007) proposed a stratification that is more a continuum than a dichotomy.

Since this stratification is not based on age, it does not necessarily lead to different thinking, knowledge building and transmission patterns between the different generations. It rather means that the patterns are distinctive to specific groups within both generations.

Other authors ((McKenzie, 2007), (Bennet \& Maton, 2010), (Helsper \& Eynon, 2010)) even argue the very way Prensky has set the dichotomy. (McKenzie, 2007), for instance, not only disagrees with Prensky's division among generations, but also questions the grounds of logic that led to the Digital Immigrants/Digital Natives divide.

(Even Prensky, 2009) himself, influenced by development of human - technology relations and results of other researches ((Gardner, 2000), (VanSlyke, 2003), (McKenzie, 2007), (Carr, 2008)), has changed the way he described the divide. Since he found the Digital Immigrants/Digital Natives dichotomy less relevant in new circumstances, he moved the accent of his interest from the divide to thinking of more efficient ways to enhance human abilities by an appropriate use of new technologies.

Visitors/ residents continuum

The Digital Native/Digital Immigrant dichotomy can be considered in terms different than those of the generational gap. The gap is narrowing as Digital Immigrants get integrated into the digital society, and more Digital Natives take positions (like educator, employer, etc.) earlier widely attributed to Digital Immigrants exclusively. (VanSlyke, 2003) notes "that we should conceive of the cultural assimilation between Digital Natives and Immigrants as a mutual process of adaptation rather than a one-way street." Based on this notion, he concludes that "The native/immigrant analogy can help us understand the differences between those who are comfortable with technology and those who are not". There are more evidences suggesting that the divide is more due to the context than to the age ((Bullen et al., 2011), (White \& Le Cornu, 2011), (Bennett \& Maton, 2010), (Oblinger $\&$ Oblinger, 2005)). The same technology can have different level of influence under different circumstances. The level of influence depends on the person's need for the technology to understand or 
solve a problem under given conditions. Similarly, a person can behave in different ways using the same technology in various contexts.

Having in mind that the modern ICT usage means using Web services mostly, it is reasonable to consider a new typology that describes a persons' habits and relation with Web and ICT regardless on his/her age. The first step toward it is defining the use of place metaphor in order to describe "being in a virtual place" ((Johnston, 2009), (Wenger et al., 2009). (White \& Le Cornu, 2011) propose that "place is primarily $a$ sense of being present with others". In accordance with the time spent in "Web places", activities conducted during that time, quality of interactions between the person and technology and, to some degree, results achieved by the person, there are two types of approach to technology use: Visitors and Residents (White \& Le Cornu, 2011).

It is clear that the Visitors/Residents typology is not meant to replace the Immigrant/Native dichotomy. We can use the Visitors/Residents typology to describe patterns of behavior of a person achieving a goal within more or less "computerized" environment. It has nothing to do with the person's age. Even more, the same person may not belong to the same Visitor/Resident type all the time, as he/she can behave as a Visitor in one situation and as a Resident in another. The key issue that determines the behavioral pattern is context. Individuals may be able to place themselves at a particular point along this continuum rather than in one of two boxes (White \& Le Cornu, 2011). A very small number of individuals can, therefore, be described as 'total' Residents or Visitors.

\section{METHOD}

The aim of this study is to determine whether the Digital Natives/Immigrants dichotomy and/or Residents/Visitors continuum can be applied to our students and teachers groups. If yes, it is important to disclose factors that shift an individual's or group's behavior toward one or another end of the classification. We paid special attention to permanency or inconstancy of the classification. Finally, answers to these questions would help us find more efficient ways to organize an ICT-enriched instruction that would successfully employ resources of all its participants, regardless on their age or position.
For these reasons we conducted a survey about:

1. Availability of ICT to our teachers and students at home and school,

2. Ways they use available ICT in teaching/learning process, and

3. Habits they have in communication and interactions with each other in an ICTenriched environment.

\subsection{Research design}

We used quantitative data to compare behavioral patterns of students and teachers in an ICTempowered instruction environment. Answers to the survey questions were coded in " $0-1$ " form. Series of Wilcoxon Rank Sum (WRS) tests were conducted in order to determine if the groups of students and teachers come from the same population, i.e. whether they belong to different groups in Digital Natives/Immigrants dichotomy or Visitors/ Residents analogy.

\subsection{Sampling}

The survey was divided into two parts - two separate surveys. The first survey covered 1239 students aged from 7 to 18 (with average 12.88 years and $\mathrm{SD}=3.42$ ), and 371 teachers from 21 primary and secondary schools in southern regions of Serbia, mostly from rural background. Teachers' age ranged from 26 to 62, with average 43.42 years and SD = 10.76. The sample for the second survey was comprised of 11 Mathematics and Informatics teachers and 34 students from "Nikola Tesla" Engineering School in Leposavić, Serbia. They had the same cultural background as the participants to the first survey. The only difference between the samples was the way Mathematics instruction process was organized. The students and teachers included in the second survey had successfully taken part in an ICTenriched Mathematics instruction including GeoGebra usage in Mathematics lessons ((Ljajko et al., 2010), (Ljajko \& Maksić, 2011), (Ljajko \& Ibro, 2013)).

\section{DATA COLLECTION AND ANALYSIS}

All participants in both surveys were asked to fill in a simple form containing questions referring to their access to computers and internet at home, their habits in using basic and educational software, and communication habits in ICT environment.

\section{Mathematics}


Data we gathered in the first survey show that the schools were poorly equipped with ICT, as opposed to majority of schools in Serbia. This could be expected, since the least developed regions of Serbia are its southern ones. Namely, there were 3 schools out of 21 without a computer classroom and additional four had no internet access. Even despite such a low ICT access in schools, a well scheduled instruction with properly prepared instruction by skillful teachers would show improvement in terms of quality and results achieved by students. (Ljajko et al. 2010; Ljajko \& Ibro 2013).

Both teachers and students included in the first survey had much higher accessibility to computers and internet at home, table 1 . The same table presents the ways students and teachers use computers and Internet for learning/instructing purposes and in communication in the instruction process.

Table 1. The first survey - distribution of students' $\left(n_{1}=1239\right)$ and teachers' $\left(n_{2}=371\right)$ answers.

\begin{tabular}{lcccc}
\hline & \multicolumn{2}{c}{ Students } & \multicolumn{2}{c}{ Teachers } \\
\hline & Count & $\%$ & Count & $\%$ \\
Q1. Have access to a computer at home? & 1079 & 87 & 345 & 93 \\
Q2. Have access to Internet at home? & 1067 & 86 & 343 & 92 \\
Q3. Use basic Office programs? & 678 & 55 & 217 & 58 \\
Q4. Use computers to learn/prepare instruction? & 644 & 52 & 190 & 51 \\
Q5. Use e-mail to communicate teachers/students? & 905 & 73 & 136 & 37 \\
Q6. Have social network account/s? & 1018 & 82 & 107 & 29
\end{tabular}

The reason why participants of the second survey were separated was that most of the Mathematics lessons in the school were conducted in an ICTenriched environment using GeoGebra software ((Ljajko \& Ibro, 2013), (Ljajko \& Maksić, 2011), (Ljajko et al., 2010)). As a result, the teaching/learning process was not restricted to school only, but the students and teachers could invest their resources into the process at any time and place they found appropriate. (Ljajko \& Ibro, 2013). This means the instruction process was reshaped into a "virtual place". Thus, taking part in the instruction process was, in fact, their presence at a "virtual place", as some authors propose, ((Johnston, 2009), (Wenger et al., 2009), (White \& Le Cornu, 2011)).

The data about the indicators are shown in Table 2.

Table 2. The second survey - distribution of students' $\left(n_{1}=34\right)$ and teachers $\left(n_{2}=11\right)$ answers.

\begin{tabular}{lccccc}
\hline & Students & \multicolumn{3}{c}{ Teachers } \\
\hline & Count & $\%$ & Count & $\%$ \\
Q1. Have access to a computer at home? & 34 & 100 & 11 & 100 \\
Q2. Have access to Internet at home? & 32 & 94 & 11 & 100 \\
Q3. Use basic Office programs? & 31 & 91 & 11 & 100 \\
Q4. Use computers to learn/prepare instruction? & 33 & 97 & 10 & 91 \\
Q5. Use e-mail to communicate teachers/students? & 34 & 100 & 10 & 91 \\
Q6. Have social network account/s? & 34 & 100 & 9 & 82 \\
\hline
\end{tabular}


Our idea with the separate survey was to find out if there is a possible influence of such a computer usage in the instruction process to behavioral patterns of students and teachers in an ICT-enriched environment.

Therefore, our aims were to:

1. Find out if the groups of students and teachers within the school are significantly different to each other concerning behavior in ICT-enriched environment.

2. Compare their accessibility to ICT at home, the ways and habits they show in ICT usage in the instruction process to the corresponding indicators of the overall population in the first survey.

\section{RESULTS}

Every question in the tables 1 and 2 was used as a criterion to a WRS test. In every of the WRS tests the null hypothesis was:

$H_{0}$ : The two samples come from the same population, i.e. there is no statistical difference between the groups.

Therefore, the alternate hypothesis would be:

$H_{1}$ : The two samples do not come from the same population.

\subsection{The first survey}

1. First two questions were meant to reveal the degree of availability of ICT to teachers and students at home.

As a result to the WRS test for the first question data, we obtained the $z$-value

$$
z=1.7498<1.96=z_{0.025} .
$$

The WRS test for the second question gave the $\mathrm{z}$-value

$$
z=1.8535<1.96=z_{0.025} .
$$

Having in mind the z-values we obtained, we can accept the null hypothesis at $95 \%$ confidence level for both cases. In other words, there is no difference between teachers and students, meaning they do not belong to different social groups that would be defined by having access to a computer or Internet respectively.

2. The purpose of the third and fourth questions was to find out if there was a difference between the samples concerning the ways the participants use ICT in instruction process.

The results of the third WRS test show that the $\mathrm{z}$-value is

$$
z=1.1027<1.96=z_{0.025} .
$$

The $\mathrm{z}$-value in the fourth case was

$$
z=-0.2237 \Rightarrow|z|<1.96=z_{0.025} .
$$

Both z-values show that the null hypothesis can be accepted at $95 \%$ confidence level, i.e. both samples come from the same population defined by ICT usage in the instruction process. Apart of that, it is evident that relatively small shares of both groups use ICT for educational purposes.

3. Answers to the last two questions were used to reveal information about the habits the participants have in communication with each other in an ICT-enriched environment.

The z-value we obtained through a WRS test for the fifth question was

$$
z=-10.6453 \Rightarrow|z|>1.96=z_{0.025} .
$$

Concerning the social network accounts, the difference is even sharper and the corresponding z-value we obtained through a WRS test was

$$
z=-15.5938 \Rightarrow|z|>1.96=z_{0.025} .
$$

Both z-values show that the null hypothesis can be rejected in favor of the alternate one at $95 \%$ confidence level, i.e. the samples come from the different populations defined by participants' habits in ICT usage to communicate each other in the instruction process.

All these show that the difference between students and their teachers is statistically significant only concerning their habits in ICT usage for communication purposes. Further research would be needed to reveal if these habits are restraints or can be helpful for the teaching/learning process.

\subsection{The second survey}

We applied the same type of WRS tests to the data gathered in the second survey. Series of WRS tests gave following results:

1. According to answers to the first question, we learnt that all of the students and teachers covered with the second survey had access to computers at home. Only two students had no internet access at home. Clearly, the corresponding z-values were 


$$
z=0<1.96=z_{0.025}
$$

for the first question, and

$$
z=0.2905<1.96=z_{0.025}
$$

for the second one.

2. For the third question we obtained $\mathrm{z}$-value

$$
z=0.4358<1.96=z_{0.025},
$$

and for the fourth one the $\mathrm{z}$-value was

$$
z=-0.3037 \Rightarrow|z|<1.96=z_{0.025} .
$$

Though the difference between the groups was not statistically significant concerning these two criteria in the first survey, too, comparing results of the first survey to the results of the second survey, one can notice a sharp increase in percentage for both groups from $54.72 \%$ to $97.06 \%$ for students, and from $54.89 \%$ do $90.91 \%$ for teachers.

3. Participants' habits in communication related to the instruction process in an ICT environment were judged according to their answers to the last two questions. The WRS test applied on data gathered in the fifth question gave $\mathrm{z}$-value

$$
z=-0.4490 \Rightarrow|z|<1.96=z_{0.025} .
$$

The resulting $\mathrm{z}$-value for the sixth question was

$$
z=-0.8980 \Rightarrow|z|<1.96=z_{0.025} .
$$

In this case, the increase in percentage was much sharper for the group of teachers - from $28.57 \%$ to $81.82 \%$.

The results of the second survey show that the null hypothesis can be accepted at $95 \%$ confidence level, which means there is no statistically significant difference between the groups of students and teachers within this school concerning any of the criteria.

\section{DISCUSSION AND CONCLUSION}

The data analysis shows that the groups in the first survey were different only concerning the habits participants showed in communication using ICT tools. Students tend to use ICT in communication between each other and with their teachers far more frequently than their teachers do. Still, a closer look at percentages in the Table 1 reveals that the same group of participants shows different behavioral patterns at different aspects of their activities. Both groups confirmed very seldom ICT usage for instruction

\begin{tabular}{|c|c|c|c|c|}
\hline & \multicolumn{2}{|c|}{ Sample 1} & \multicolumn{2}{|c|}{ Sample 2} \\
\hline & Students & Teachers & Students & Teachers \\
\hline Q1 & $\mathrm{N}(\mathrm{R})$ & $\mathrm{N}(\mathrm{R})$ & $\mathrm{N}(\mathrm{R})$ & $\mathrm{N}(\mathrm{R})$ \\
\hline Q2 & $\mathrm{N}(\mathrm{R})$ & $\mathrm{N}(\mathrm{R})$ & $\mathrm{N}(\mathrm{R})$ & $\mathrm{N}(\mathrm{R})$ \\
\hline Q3 & $\mathrm{I}(\mathrm{V})$ & $\mathrm{I}(\mathrm{V})$ & $\mathrm{N}(\mathrm{R})$ & $\mathrm{N}(\mathrm{R})$ \\
\hline Q4 & $\mathrm{I}(\mathrm{V})$ & $\mathrm{I}(\mathrm{V})$ & $\mathrm{N}(\mathrm{R})$ & $\mathrm{N}(\mathrm{R})$ \\
\hline Q5 & $\mathrm{N}(\mathrm{R})$ & $\mathrm{I}(\mathrm{V})$ & $\mathrm{N}(\mathrm{R})$ & $\mathrm{N}(\mathrm{R})$ \\
\hline Q6 & $\mathrm{N}(\mathrm{R})$ & $\mathrm{I}(\mathrm{V})$ & $\mathrm{N}(\mathrm{R})$ & $\mathrm{N}(\mathrm{R})$ \\
\hline
\end{tabular}
purposes. For these reasons, we characterized both groups as one of the groups within Digital Native/Immigrant (N/I) or Resident/Visitor (R/V) divisions, as Table 3 shows:

Table 3. Characterization of groups according to their behavior in the ICT environment.

On the other hand, the groups in the second survey were very similar to each other concerning this criterion. Both surveys covered population with the same cultural background. The main difference between the populations was the way they did Mathematics instruction in the same period. Namely, the second survey covered students and teachers that were included in an ICT-empowered
Mathematics teaching/learning process using GeoGebra software.

In the first sample, students are mostly identified as Digital Natives (Residents) and teachers mostly as Digital Immigrants (Visitors), while in the second sample, both groups behave as Digital Natives (Residents). Though it looks like the main result of the ICT- empowered instruction was making the groups equal concerning communication habits in 
the instruction process, the real advancement can be noticed in ICT usage for educational purposes for both groups.

Having in mind participants' answers, their behavioural patterns and the results we obtained through WRS tests, we can draw several conclusions:

1. By an appropriate introduction of ICT into the instruction process, it is being transformed into a "virtual place" for both students and teachers. Apart of school classes, both students and teachers feel to be at their common "virtual place", i.e. instruction process at any place or time they find suitable, which is in accordance with the notion of "virtual place" introduced by Johnston (2009), Wenger, et al. (2009) or White \& Le Cornu (2011). Of course, in this way all participants of the instruction process employ their resources at much higher level than they did at school only.

2. Behavior of social groups and individuals in particular highly depends on the context. Two groups - teachers and students, apparently very different in age, showed two different communication habits in one case (the first survey - no ICT included in the instruction process), but in another case (the second survey - ICT included in the instruction process) the habits were almost identical for both groups. On the other hand, two groups of the same age or with same predispositions behave in one way when the lessons were held in an ICTempowered environment, and in another way when the instruction process was deprived of ICT usage.

3. Comparing results of both surveys, we see that the group of teachers showed a shift in a segment of their behavior (communication habits) towards the way students did regardless on the context. This may suggest that the instruction process in an ICT-empowered environment should be organized through teachers' adaptation to students' behavior. However, conclusions should be drawn only if the situation as a whole is observed, and not by taking into consideration isolated parts of information.
This will be discussed in the next conclusion.

4. Finally, answers to the second set of questions in both surveys reveal a sharp increase in ICT usage for educational purposes for both groups simultaneously, which supports the idea of "conceiving of the cultural assimilation between Digital Natives and Immigrants as a mutual process of adaptation rather than a oneway street.", (VanSlyke, 2003). Therefore, a proper ICT usage in the instruction process can help in integration of groups of teachers and students different in age into a single group, defined by the very ICT environment, successful in accomplishing the task of building new knowledge by students.

Further researches are needed to define most effective ways to arrange relations between participants, technology and subject material in the ICT- empowered instruction process in order to achieve better results.

\section{RERERENCES}

Bennett, S., \& Maton, K. 2010. Beyond the 'digital natives' debate: Towards a more nuanced understanding of students' technology experiences. Journal of Computer Assisted Learning, 26, pp. 321-331.

Bullen, M., Morgan, T., \& Qayyum, A. 2011. Digital Learners in Higher Education: Generation is Not the Issue. Canadian Journal of Learning Technology, 37(1), pp. 1-24.

Carr, N. 2008. Is Google making us stupid?, What the internet is doing to our brains. The Atlantic, 301(6), pp. 56-63.

Cunningham, B. 2007. Digital Native or Digital Immigrant, Which Language Do You Speak?.NACADA Clearnighouse of Academic Advising Resources. Retrieved from http://www.nacada.ksu.edu/Resources/Clearingho use/View-Articles/Digital-natives-and-digitalimmigrants.aspx\#sthash.GhqjNVgH.dpuf

Gardner, H. 2000. Intelligence reframed: Multiple intelligences for the 21st century.New York: Basic Books.

Helsper, E.J., \& Eynon, R. 2010. Digital natives: Where is the evidence?. British Educational Research Journal, 36, pp. 503-520.

Herceg, D. 2007. Matematika i računari u školi. In Tehnologija, informatika i obrazovanje za drustvo ucenja i znanja - Zbornik radova., pp. 470-475. 
Howell, J. 2012. Teaching with ICT: Digital pedagogies for collaboration and creativity.Melbourne: Oxford University Press.

Ibro, V.D. 2011. Didakticko-metodicke mogucnosti unapredjenja nastave matematike u osnovnoj skoli.Leposavic: Faculty of Teacher Education.

Johnston, R. 2009. Salvation or destruction: Metaphors of the Internet. First Monday, 14, pp. 4-6.

Jukes, I., Mccain, T., \& Crockett, L. 2010. Understanding the Digital Generation: Teaching and Learning in the New Digital Landscape.Melbourne, Vic: Hawker Brownlow Education

Kelly, F.S., Mccain, T., \& Jukes, I. 2009. Teaching the digital generation: No more cookie-cutter high schools.Melbourne, Vic: Hawker Brownlow Education.

Ljajko, E., Mihajlović, M., \& Pavličić, Z. 2010. The hyperbola and GeoGebra in high - school instruction. Teaching Mathematics and Computer Science, 8(2), pp. 277-285.

Ljajko, E., \& Maksić, J. 2011. Proucavanje elipse pomocu GeoGebre. Osjecki matematicki list, 11(1), pp. 39-44.

Ljajko, E., \& Ibro, V. 2013. Development of ideas in a GeoGebra - aided mathematics instruction. Mevlana International Journal of Education, 3(3), pp. 1-7.

Mckenzie, J. 2007. Digital nativism, digital delusions, and digital deprivation. The Educational Technology Journal,17(2). From Now On.

Mcnierney, D.J. 2004. Case study: One teacher's odyssey through resistance and fear. TechTrends, 48(5), pp. 64-69. doi:10.1007/BF02763533

Oblinger, D., \& Oblinger, J. 2005. s it Age or IT: First steps towards understanding the net

\footnotetext{
*E-mail: eugen.ljajko@pr.ac.rs
}

generation?. In D. Oblinger\& J. Oblinger Eds., Educating the Net Generation.Boulder, CO: EDUCAUSE.. pp. 2.1-2.20.

Prensky, M. 2001. Digital Natives, Digital Immigrants Part 1. On the Horizon, 9(5), pp. 1-6.

Prensky, M. 2001. Digital Natives, Digital Immigrants Part 2: Do they really think differently. On the Horizon, 9(6), pp. 1-6.

Prensky, M. 2009. H. sapiens digital: From digital immigrants and digital natives to digital wisdom. Innovate, 5(3).

Strategija razvoja obrazovanja u Srbiji do 2020 godine 2013. Government of the Republic of Serbia. Retrieved from http://www.srbija.gov.rs/vesti/dokumenti_sekcija. php?id $=45678$

Tapscott, D. 2009. Grown up digital: How the Net Generation is Changing Your World.New York: McGraw-Hill.

Toledo, C.A. 2007. Digital Culture: Immigrants and Tourists Responding to the Natives' Drumbeat. International Journal of Teaching and Learning in Higher Education, 19(1), pp. 84-92.

Vanslyke, T. 2003. Digital natives, digital immigrants: Some thoughts from the generation gap. The Technology Source, Commentary.

Wenger, E., White, N., \& Smith, J.N. 2009. Digital Habitats - Stewarding Technology for Communities.Portland, OR: CPsquare.

White, D.S., \& Le Cornu, A. 2011. Visitors and Residents: A new typology for online engagement. First Monday, 16(9-5).

Zur, O., \& Zur, A. 2011. On Digital Immigrants and Digital Natives: How the Digital Divide Affects Families, Educational Institutions, and th

Workplace.Zur Institute. Online Publication. Retrieved from http://www.zurinstitute.com/digital_divide.html 